\title{
ALGUNAS CUESTIONES SOBRE LA LABOR DEL JUEZ EN LA HISTORIA RECIENTE
}

Artículo que sienta las bases para iniciar una crítica al problema de los valores en la jurisprudencia, en línea con las tesis mantenidas por Schmitt y Forsthoff sobre la tiranía de los valores.

\author{
Autor: Isabel Ruiz-Gallardón ${ }^{1}$ \\ Profesor Contratado Doctor, Universidad Rey Juan Carlos (Madrid)
}

\section{Resumen}

Muchos de los criterios tradicionales de interpretación reciben, en el marco del pensamiento orientado a valores, una nueva perspectiva que convierte al juzgador en un colaborador activo en la creación del orden jurídico. Este ensanchamiento de la labor creadora e interpretativa de los jueces no es incompatible con los principios de primacía de la ley y de sujeción del juez a ella. Supone, más bien, una superación del conceptualismo jurídico sustituyéndolo por métodos más flexibles, y una ampliación de la función interpretativa del juzgador. Este artículo plantea un campo de investigación en el que, a partir del análisis histórico

\footnotetext{
${ }^{1}$ Isabel.ruizgallardon@urjc.es
} 
de la labor del juez, queden sentadas las bases para iniciar una crítica al problema de los valores en la jurisprudencia.

Palabras Clave: jurisprudencia; justicia; derecho; método; valores.

\title{
Some considerations concerning judges duty in recent history
}

\begin{abstract}
Many traditional interpretation criteria are, in the context of values-oriented thinking, a new perspective that makes the judge an active collaborator in the creation of legal order. This broadening of the creative and interpretive work of judges is not inconsistent with the principles of supremacy of law. It implies, rather, an overcoming of legal conceptualism replacing more flexible methods and an extension of the interpretative role of the judge. This article proposes a research field in which, considering the historical analysis of the judge's work, bases are settled to initiate a review of the problem of values in case law.
\end{abstract}

Key Words: case law; justice; law; method; values

\section{JUECES Y LEGISLADORES ANTE LA CREACIÓN DE DERECHO}

\subsection{El legislador y la doctrina jurídica}

El progreso es fruto de las continuas rupturas de la conciencia moral general hacia nuevos contenidos de vivencia; es una exigencia de las situaciones vitales que aparecen y que ni siquiera pudieron ser pensadas. ${ }^{2}$

La adaptación del derecho a la sociedad siempre cambiante constituye una preocupación para los juristas. El derecho romano, tan arraigado en el espíritu que vitaliza la mayoría de los sistemas jurídicos occidentales, nos presenta continuas rupturas ético jurídicas de situaciones puramente formales y, al mismo tiempo, petrificadas. La aplicación de la jurisprudencia del Tribunal del Reich, después de la Segunda Guerra Mundial, constituye, quizás, el caso más contundente, en nuestro siglo, de ruptura de una justicia puramente formal en favor de sus contenidos materiales y absolutos. Esta ruptura pretende volver al ideal aristotélico de justicia que exige retribuir la prestación de un modo materialmente equivalente y

${ }^{2}$ Hegel, Georg Wilhelm, Lecciones sobre la Filosofía del a Historia Universal, prólogo de Ortega y Gasset, José, advertencia y traducción del alemán de Gaos, José, ed. Alianza, Madrid, $5^{\text {a }}$ reimpr. de 1994, p. 75 . 
socialmente justo. Con el paso del estado liberal al estado social de derecho, fruto de la nueva fórmula organizativa de las constituciones modernas, esta exigencia parece incluso más necesaria. El estado social busca establecer unos mínimos de dignidad humana garantizados por el poder político, no solo con el respeto a la libertad individual sino también con la intervención activa en pro de la consecución de los mismos.

¿Cuál es la misión del legislador y de la doctrina ante estos acontecimientos? Parece claro que no les corresponde aprobar o alentar rupturas semejantes, pues ello supondría abandonar la idea de la justicia intemporal —a la que, en todo caso, han de acercarse en el establecimiento de sus principios, si bien condicionados por las distintas circunstancias de las relaciones jurídicas-e incluso verse ellos mismos acusados de injusticia. El derecho legal no puede, en todas las decisiones definitivas, declararse a sí mismo como algo que carece permanentemente de validez. Pero el legislador debe darse cuenta de lo relativo y temporal de sus planificaciones.

Por otra parte, queda el problema de saber hasta qué punto el juez se hace profesional y políticamente responsable de semejante ruptura jurídica. Desde un punto de vista estricto, se podría decir que actúa bajo su propia conciencia. En realidad, sin embargo, sus decisiones son legítimas en la medida en que se mantengan dentro de los claros límites del ámbito de actuación que desde siempre ha reservado a la jurisprudencia el arte judicial profesional. Con todo, en la determinación de estos límites y, con mayor motivo, después de su transgresión, su actuación supone un riesgo para la seguridad jurídica. ¿Debe entonces decidir aquí no tanto según su responsabilidad exterior, cuanto por criterios de equidad, aunque ello conlleve la posible consecuencia de poner en peligro la certeza del Derecho?

El legislador puede y debe codificar las rupturas ya producidas. Pero estas rupturas suelen tener su primera manifestación en los tribunales. A lo largo de la historia la actividad creativa del juez ha tenido diferente acogida. Los periodos de aceptación coinciden en general con los periodos de gran confianza en el juzgador, de espontaneidad jurídica y social. Los de restricción o negación, con las fases de desarrollo legislativo y de codificación. ${ }^{3}$

Desde finales del siglo XX, la polémica entre los partidarios del derecho estricto y los de un derecho flexible ha tomado la forma de un debate acerca de la respectiva preferencia que ha de concederse a las reglas (standards o directivas). En general, la ciencia actual ha llegado al convencimiento de que ambas formas son necesarias y deben ser conciliadas: junto a la norma, hay que tomar en consideración los elementos genéricos e individuales de los casos jurídicos ${ }^{4}$.

\footnotetext{
${ }^{3}$ Referencia de Larenz, Karl, en La Filosofía Contemporánea del Derecho y del Estado, edit. Revista de Derecho Privado, Traducción E. Galán Gutiérrez y A. Truyol y Serra. Prólogo Luis Legaz Lacambra, Madrid, 1942, p. 129.

${ }^{4}$ Legaz y Lacambra, Luis, Filosofía del Derecho, Barcelona, edit. Bosch, 1979, $5^{\text {a }}$ ed. revisada y aumentada, p. 464.
} 


\section{ISABEL RUIZ-GALLARDóN}

A todo esto hay que añadir la diferente consideración que merece la actividad del juez en los dos grandes sistemas de producción jurídica que se han desarrollado a lo largo de la historia de Occidente y se mantienen en la actualidad: el sistema de formulación judicial del derecho y el sistema de formulación legislativa.

Estos sistemas de producción normativa - legislativo y judicial- se manifiestan en los dos grandes sistemas jurídicos que en el actual mundo occidental imperan: el que se llama romano, romanizado o de derecho civil (esta última expresión la adoptan los juristas ingleses, porque tiene su origen en el Corpus Iuris Civilis, difundido y perfeccionado por las escuelas de glosadores y comentaristas en toda Europa y transmitido después, principalmente por España, al continente americano) y el anglosajón o de Common Law; en éste conserva la primacía la costumbre general o jurisprudencial, Common Law, aunque el derecho escrito cada vez progresa más en los países que se rigen por estas fuentes.

En definitiva, en el sistema romano, el derecho adopta la forma predominantemente legal y codificada, mientras que en el Common Law es de especial importancia la costumbre y el precedente judicial. A su vez, los ordenamientos legislativos y jurisdiccionales pueden ser de tipo común o especial; en uno y otro caso la equidad y la flexibilidad del juez en sus decisiones juegan un papel diferente. ${ }^{5}$

\subsection{El juez: garante de la seguridad jurídica e instrumento de adaptación a los cambios}

Si predominara la libertad del juez para aplicar de manera flexible las normas, ello significaría la desaparición del derecho, que se diluiría peligrosamente en la moral y en la política. Al perder el derecho sus cualidades de precisión, racionalidad, estabilidad y seguridad se vería privado de cualidades y características que le son esenciales para el logro de su finalidad de definir y delimitar los derechos y deberes de los individuos y agrupaciones sociales. Pero un exclusivo imperio de la ley, sin discrecionalidad alguna por parte de los jueces, sería también la muerte del derecho, pues le impediría resolver con justicia los casos particulares.

El derecho no puede ser ni totalmente rígido y formal ni puramente equitativo. ${ }^{6}$ Ya en la época clásica los filósofos griegos percibieron esto. Aristóteles fue el primero en hacer alusión al concepto de justicia moderada que, más tarde, se convertirá en la equidad. La teoría aristotélica de la justicia busca un término medio en la aplicación de la justicia; para ello, cree necesario que se establezca un patrón de justicia, promulgando normas generales, pero a la vez considera

${ }^{5}$ Ruiz-Gallardón, Isabel, Una aproximación a la equidad desde la teoría y la dogmática jurídicas, servicio de publicaciones de la Universidad Complutense de Madrid, Madrid, 2002. pp. 33-45.

${ }^{6}$ Stenberg, Theodor, Introducción a la Ciencia del Derecho, Barcelona, edit. Labor, 1930 (hay una $2^{\text {a }}$ ed.: 1940; traducción de Rovira), pp. 23-27. 
que hay que dejar un cierto margen a la discreción individual de los magistrados. Ante estas consideraciones, debemos hacernos las siguientes preguntas, ien qué términos y en qué medida han de ser combinados el derecho estricto y el derecho equitativo?, ¿qué política han de seguir las leyes en orden al margen que ha de ser concedido al arbitrio de los jueces?

Las circunstancias sociopolíticas de cada país y su situación jurídica determinan el grado de aplicación, mayor o menor, de la equidad. De esta forma, la remisión al arbitrio de equidad está indicada en momentos de crisis o de renovación jurídica, o cuando se trate de aquellas partes del derecho de reciente formación que todavía no cuenta con una reglamentación jurídica completa. Además, el problema político-legislativo del arbitrio de equidad depende mucho de la naturaleza y peculiaridades de las diversas materias que constituyen el clásico ordenamiento del derecho privado. En conclusión, en aquellas instituciones en que las exigencias de la seguridad jurídica son primordiales, debe predominar el derecho rígido y formalista. Pero cuando imperan las necesidades de adaptación y evolución, son el derecho flexible y la equidad los que deben predominar.

Muchos juristas del siglo XX abandonaron aquellas teorías que veían en la ley la sola y exclusiva fuente de derecho. "Quien no comprende —escribe Spota-que el derecho no está dado sólo en la ley escrita, hállase en grave peligro de no valorar adecuadamente el derecho vivo que se da a través de la experiencia jurídica, o mejor dicho, de esa fecunda y notable fuente del derecho que es la jurisprudencia"?.

Como ya hemos apuntado, el problema que se plantea es la contradicción que se da en la aplicación del derecho, entre los criterios de justicia y de seguridad jurídica; ésta última exige positividad, generalidad, derecho formal preestablecido que valga independientemente de la justicia y sus fines. Por otro lado, "la justicia y sobre todo, la finalidad, exigen individualización jurídica, adaptación, derecho libre y equitativo." ${ }^{8}$ La solución está en el término medio: ni ley sin arbitrio de equidad ni equidad sin ley positiva. De esta forma se logrará reconciliar las exigencias de la ley y de la vida. Ninguna de estas dos dimensiones de la justicia puede ser relegada a un segundo plano pues ambas han contribuido a la formación del derecho presente. Además, la criticada imprecisión de la equidad se evita en gran medida si no se la desliga de la idea de justicia y finalidad, base moral e ideal del derecho. ${ }^{9}$

La aplicación de las normas supone una actividad creadora, en cuanto que el que interpreta da sentido, desarrolla y completa la ley; pero no significa la concesión de un poder arbitrario al juez para basar sus decisiones en sus parti-

${ }^{7}$ Spota, Alberto G., Tratado de Derecho Civil, Tomo I, parte general, vol. 1, Buenos Aires, edit. Depalma, 1947, prefacio: pp. 7-11.

${ }^{8}$ Radbruch, Gustav, Filosofía del Derecho, ed. Revista de Derecho Privado, 4 ed., Madrid, 1959, p. 98.

${ }^{9}$ Castán Tobeñas, José, La formulación judicial del Derecho: jurisprudencia y arbitrio de equidad, $2^{\mathrm{a}}$ ed. revisada y aumentada, edit. Reus, Madrid, 1954, p. 157. 
culares sentimientos o en sus utópicos ideales de legislador; al juez se le confiere el officium de cooperar en la realización del derecho, y en su cumplimiento está sometido a las leyes y guiado por los principios generales del derecho. ${ }^{10}$

\section{TESIS DOCTRINALES DE LA PRIMERA MITAD DEL SIGLO XX QUE INFLUYEN EN LA CONSIDERACIÓN DE LA LABOR DEL JUEZ}

\subsection{Positivismo: separación doctrinal entre ser y deber ser}

El positivismo se desarrolla bajo las influencias inmediatas de la filosofía social positivista de Auguste Comte, de los filósofos ingleses (Bentham y Stuart Mill) y de las ciencias naturales, en especial de la "doctrina evolucionista" de Darwin. Tuvo lugar, en gran medida, una reanudación del antiguo empirismo, de la psicología asociacionista de Locke y, en la ciencia del derecho, también de la ética utilitarista de Thomasius ${ }^{11}$.

El positivismo aspira a desterrar de la ciencia toda metafísica. En alguna de sus manifestaciones incluso se abstiene de entrar en cualquier cuestión acerca de "valores" o "validez" y restringe la ciencia estrictamente a los hechos y a su legalidad empíricamente observable. Según la concepción positivista, lo único que es accesible al conocimiento científico, prescindiendo de la lógica y la matemática, son los hechos perceptibles junto con la legalidad que en ellos se manifiesta.

La necesidad de una auto-reflexión metódica de la ciencia del derecho es aportación de Hans Kelsen. Este autor entiende la Teoría Pura del Derecho como una teoría del derecho positivo, y, en este sentido, como una teoría general del derecho, la cual no es interpretación de normas jurídicas especiales, nacionales o internacionales, pero ofrece, justamente sobre la base de una teoría general del derecho positivo, una teoría de la interpretación jurídica. De este modo, la teoría pura del derecho se diferencia de la tradicionalmente llamada dogmática jurídica, que pretende conocer un determinado derecho positivo en su contenido especial y en su conexión sistemática. En contra de esto, la teoría pura del derecho no se ocupa de los contenidos, sino de la estructura lógica de las normas jurídicas; examina el sentido, la posibilidad y los límites de un enunciado jurídico en general (no de un determinado enunciado jurídico) y la clase y modo de su realización ${ }^{12}$.

La tesis fundamental de Kelsen es la afirmación de una "completa disparidad entre ser y deber ser". El "deber ser" no puede reducirse ni a un "querer" de aquél que establece la norma -pues el "querer" es un fenómeno psíquico y fáctico y

\footnotetext{
${ }^{10}$ Ruiz-Gallardón, Isabel, op. cit., véase el capítulo 1.

${ }^{11}$ Larenz, Karl, Metodología de la Ciencia del Derecho, Ariel, Barcelona, 1994, p. 57.

${ }^{12}$ Kelsen, Hans, Teoría Pura del Derecho, edit. Porrúa, 9ªed. México, 1997, pp.15-16.
} 
pertenece, por tanto, a la esfera del ser - ni una conducta de quien debe. No es algo psíquico real, sino el sentido de un acto, con el que se preceptúa o permite, y especialmente se autoriza, una conducta.

La distinción entre ser y deber ser, dice Kelsen, no puede explicarse más; está dada inmediatamente a nuestra conciencia. Nadie puede negar que de algo que es, no puede seguirse que debe ser, como de algo que debe ser, no puede seguirse que es. La ciencia del derecho tiene que ver con normas, es decir, con un deber ser, debiéndose incluir aquí también el "permitir" y el "poder".

A las normas de derecho positivo subyacen actos, es decir, fenómenos externos de conducta humana que no llevan consigo su sentido - como actos jurídicos - sino que lo reciben del hecho de que una norma es aplicada a ellos como esquema interpretativo. El que, por ejemplo, un determinado cambio de cartas signifique la conclusión de un contrato, resulta únicamente de que este hecho cae dentro de ciertas disposiciones del código civil.

La Teoría Pura del Derecho trata de la peculiaridad lógica y de la independencia metódica de la ciencia del derecho. Kelsen se opone a la unión de la ciencia del derecho y la ética y de toda metafísica jurídica. Las normas de la moral son normas, lo mismo que las del derecho positivo; es decir: son producidas por la costumbre y la creación consciente. Pero mientras que el derecho es un orden coactivo, la moral no lo es. Además, Kelsen sostiene que no se puede determinar lo que se tiene que estimar bueno o malo, justo o injusto, en todas las circunstancias y por ello, el derecho no puede distinguirse de otros órdenes coactivos (por ejemplo, el orden interno de una banda de ladrones) por el hecho de ser un orden justo. La Teoría Pura del Derecho renuncia, por tanto, a valorar el derecho positivo; como ciencia, solo debe aprehender el derecho positivo en su esencia, y comprenderlo mediante un análisis de su estructura. Una norma jurídica, dice Kelsen, no vale porque tenga un contenido determinado, sino porque ha sido creada de un modo determinado, legitimada, en último término, por una norma fundamental presupuesta ${ }^{13}$.

La objeción más importante que tiene que soportar la Teoría Pura del Derecho es la de que Kelsen no es capaz de mantener constantemente la completa disparidad entre ser y deber ser de la que parte. Un deber ser, subraya, solo puede ser constantemente referido a otro deber ser, una norma a otra norma de rango superior, de la única que resulta el sentido jurídico específico de un suceso ${ }^{14}$. La unidad de todas las normas del derecho positivo se basa en que todas ellas pueden referirse a una norma única como último fundamento de su validez: la norma fundamental del orden jurídico respectivo. Esta norma fundamental no es establecida sino que es necesariamente presupuesta por la ciencia del derecho para poder interpretar como

\footnotetext{
${ }^{13}$ Kelsen, Hans, op. cit. pp. 19-30

${ }^{14}$ Kelsen, Hans, op. cit. p. 23
} 


\section{ISABEL RUIZ-GALLARDóN}

un orden jurídico, el material de normas que le es dado; el deber ser resulta así, de hecho, indirectamente, del postulado teórico-cognoscitivo de la norma fundamental, del ser, que como tal es para Kelsen ajeno al sentido y al valor de la facticidad.

Su concepto de deber ser también ha sufrido críticas desde diferentes ámbitos de la filosofía del derecho. Kelsen habla inicialmente del deber ser ${ }^{15}$ como de una norma que vincula a sus destinatarios, que los obliga. Se sirve de expresiones que se orientan a la ética o doctrina de los deberes. Pero él no quiere entender así el deber ser. En primer lugar, para Kelsen, no se trata de rectitud o no del contenido de la norma sino que debe estar legitimado por la norma fundamental. En segundo lugar, Kelsen no considera las normas jurídicas preceptos (o prohibiciones), sino autorizaciones: normas que autorizan a un individuo a imponer a otro un acto coactivo como sanciones; En definitiva, Kelsen somete el concepto de deber ser a un cambio radical de sentido al independizarlo de la ética.

En cuanto a la doctrina de la interpretación, Kelsen solo reconoce valor cognoscitivo a la interpretación literal. Según él, solo puede llamarse ciencia un pensamiento que sea capaz de basar cada uno de sus pasos o bien en la evidencia lógica (o matemática) o en hechos ineludibles. Pero la interpretación jurídica, no es de esta índole. Mientras se sostenga que los "juicios de valor" (como tienen inevitablemente que darse en la ciencia del derecho y en la jurisprudencia de los tribunales) no puede ser proporcionados por actos de conocimiento, mientras no se haga distinción entre la lógica de las ciencias fácticas y la teleológica de las ciencias explicativas del sentido o interpretativas, la ciencia del derecho solo puede admitirse o bien como investigación científico-causal de los hechos que sirven de base a la norma jurídica (como sociología del derecho), o como una doctrina acerca de las formas lógicas de las relaciones jurídicas (como Teoría Pura del Derecho). Así, lo que el jurista considera su misión peculiar - la interpretación de normas e institutos jurídicos y el desarrollo del derecho conforme al sentido exigido por la coherencia objetiva - mediante la analogía o el desarrollo de un principio jurídico puede ser una técnica o arte de aplicación del derecho según ciertas reglas, pero no tiene el rango de ciencia ${ }^{16}$.

\subsection{Los neokantianos y su búsqueda de una fundamentación objetiva del Derecho}

La implantación estricta de las tesis positivistas del derecho tuvo consecuencias dramáticas en el ámbito del derecho aplicado por los tribunales de justicia.

En su teoría de la ciencia del derecho, Stammler intenta hacer concebible la jurisprudencia como ciencia y alejar de ella el reproche de carecer de valor

\footnotetext{
${ }^{15}$ Larenz, Karl, Metodología, op. cit., pp. 95-97.

${ }^{16}$ Larenz, Karl, Metodología op. cit., p. 103.
} 
científico $^{17}$. La ciencia del derecho para Stammler es una ciencia de fines, es decir, ordena los fenómenos según la forma de pensar, pues el Derecho es un modo del querer (no del percibir, como ocurre en las ciencias de la naturaleza donde la forma de pensar es de causa-efecto). Por ello, la ciencia del derecho forma sus conceptos de manera plenamente autónoma, independientemente de las reglas de conocimiento científico-natural.

El concepto de derecho es el de un determinado modo de establecer fines. Pero por "querer" o "establecer fines" no entiende Stammler una actividad, sino un determinado modo de pensar, que se caracteriza más en concreto porque aquí se insertan varios fines, de modo determinado y recíproco, unos como medios de los otros. Al lado de los conceptos jurídicos, Stammler admite una "praxis del derecho justo", guiada por métodos científicos, a la que no puede negarse un carácter creador. Aquí interviene otra doctrina de Stammler: la del "derecho justo"18.

Todo pensar (también el derecho) se somete a la exigencia última de la rectitud. La idea de rectitud se refiere a la perfecta concordancia de todos los contenidos de conciencia imaginables. Así, un querer jurídico particular, por ejemplo una determinada norma jurídica, solo es recta si puede adaptarse sin contradecir al conjunto de todo querer jurídico imaginable. Stammler plantea la idea de "derecho recto" como "ideal social". Afirma que no existe ningún derecho recto en sí (solo derecho positivo recto o no) pero, en conjunto, todo derecho es un intento de ser derecho recto.

Ahora bien, cuando un juez en un caso particular tiene que elegir él mismo la norma de decisión, necesita ser instruido acerca de cómo realizar esa elección en el sentido de la rectitud fundamental. Tal instrucción la ofrecen, según Stammler, los "principios del derecho recto" 19 , que no son normas jurídicas sino directrices para que el juez halle la norma jurídica adecuada al caso. Estos principios son solo medios auxiliares del pensamiento para reconocer la idea en un querer jurídico condicionado.

Las dos ideas fundamentales de Stammler de especial importancia para la metodología son: la de la independencia metódica de la ciencia del derecho frente a las ciencias de la naturaleza, que se basa en que la ciencia dogmática del derecho no pregunta por las "causas" sino por los fines y por el sentido de una norma jurídica o institución; y la segunda idea, todavía más importante, es la de que pertenece a la esencia del derecho el orientar y ordenar según una medida superior (la de la idea de derecho) el total de fines posibles en una situación dada. Stammler dio con ello un paso decisivo hacia delante en relación con la "jurisprudencia de intereses" consagrándose, por primera vez, el método teleológico en la ciencia del derecho ${ }^{20}$.

\footnotetext{
${ }^{17}$ Stammler, Rudolf, Tratado de Filosofía del Derecho, ed. Reus, 2008, Libro V, sección III.

${ }^{18}$ Stammler, Rudolf, op.cit, libro III, sec. III.

${ }^{19}$ Stammler, Rudolf, op.cit. libro III, sec. V.

${ }^{20}$ Larenz, Karl, Derecho Justo. Fundamentos de ética jurídica, trad. Luis Díez Picazo, ed. Cívitas, Madrid,
} 1993, p. 21-32. 


\section{ISABEL RUIZ-GALLARDóN}

Dentro del ámbito del neokantismo Rickert introdujo el concepto de "valor" en la metodología de las ciencias del espíritu. Presentó este concepto como un a priori teórico-cognoscitivo de las ciencias sin dar, sin embargo, respuesta a la cuestión de qué es un valor ${ }^{21}$. Sin embargo, la obra de Rickert influye en otro autor trascendente para la teoría del derecho: Gustav Radbruch. A este autor, no le importa sólo la estructura formal de pensamiento de las elecciones "referidas a valores", sino también y, especialmente, el contenido y la conexión de sentido de los valores mismos relevantes para el derecho; Radbruch lleva a cabo el tránsito de una filosofía de valores únicamente formal a otra material ${ }^{22}$.

La realidad, como tal, es siempre, para Radbruch, un dato libre de sentido y de valor. Solo la conciencia valorativa añade a las cosas un valor o desvalor. Además de esto, el hombre transforma la realidad en atención a los valores a los que aspira. La cultura surge como "el dato que tiene el significado, el sentido de realizar valores". A un valor último, que ya no es deducible, lo llama Radbruch una idea. El derecho es, en cuanto "fenómeno cultural", aquel dato que tiene el sentido de realizar la idea del derecho. La idea del derecho es el valor central, al que en última instancia está referido todo derecho como algo con sentido. Y dado que la idea del derecho es la de justicia, el derecho tiene el sentido de servir a la justicia. Esto no significa que todo derecho positivo tenga necesariamente que ser un derecho justo; pero en cuanto derecho, se halla bajo la exigencia de la justicia y se orienta a esta idea ${ }^{23}$. Esto mismo había dicho Stammler, aunque para él, la idea de derecho sólo era una pauta de enjuiciamiento, mientras que para Radbruch es a la vez principio fundamental constitutivo.

Radbruch define la ciencia dogmática del derecho como "la ciencia acerca del sentido objetivo de los órdenes jurídicos positivos" ${ }^{24}$, con ello se muestra partidario de la teoría objetiva de la interpretación. Cuando en la dogmática jurídica se habla de la voluntad del legislador, no se puede tratar, dice Radbruch, de la voluntad empírico-psicológica de determinadas personas. La ciencia dogmática del derecho ha de averiguar aquel significado de una norma jurídica que le corresponde a ésta en la estructura de sentido del orden jurídico, según el contenido significativo inherente a ella; así pues, la interpretación tiene que desarrollar y hacer visible el contenido inmanente de sentido de una norma jurídica o de un concepto jurídico, y ello sólo lo puede comprender (a diferencia de lo que dice Kelsen) refiriéndolo al fin subyacente, en último término, a la idea del derecho, y teniendo en cuenta las cambiantes necesidades jurídicas.

\footnotetext{
${ }^{21}$ Larenz, Karl, Metodología op. cit. pp. 114-117.

${ }^{22}$ Radbruch. Gustav, Introducción a la Filosofía del Derecho. traducción de W. Roces, $5^{\mathrm{a}}$ reimpr., FCE, México, 1993, p.23

${ }^{23}$ Radbruch, Gustav, Introducción op. cit. p. 35

${ }^{24}$ Radbruch. G, Introducción op. cit., p. 9
} 
Para comprender la norma jurídica particular, no solo en "sí misma" sino en la conexión de sentido de todo el orden jurídico, se precisa, al lado de la interpretación, la construcción jurídica. Por construcción entiende Radbruch el reproducir un todo de las partes antes artificialmente separadas para hacernos conscientes de la necesaria conexión de estas partes ${ }^{25}$. La verdadera construcción es la construcción teleológica, que aspira a concebir y exponer los fines de los institutos jurídicos particulares como medios para fines superiores y, en último término, para un fin supremo de todo derecho; meta, por cierto, inalcanzable ${ }^{26}$.

\subsection{La crítica al neokantismo: una mirada a la realidad}

Las tesis del neokantismo presentes en Stammler y Radbruch fueron relevadas por otras direcciones como la fenomenología de Edmund Husserl, la ética material de los valores y la ontología de Max Scheler y de Nicolai Hartmann. En esta línea, Kaufmann reprochaba al neokantismo jurídico-filosófico haber equivocado su meta de asegurar la existencia de un reino de valores absolutos, por encima de la realidad, como su punto de apoyo y pauta, porque se quedó en un racionalismo formal teórico-cognoscitivo, y porque no se atrevió a contraponer una metafísica positiva al positivismo empírico ${ }^{27}$.

El neokantismo consideraba la realidad como el producto de un proceso de transformación, cuyas condiciones básicas están situadas en la estructura de nuestro pensamiento. El hecho jurídicamente relevante es, en efecto, en relación con todo el acontecer del que es extraído, sólo el resultado de una transformación mental, a saber: de su enjuiciamiento según criterios jurídicos.

La pregunta que debemos hacernos es si un determinado suceso se convierte en una acción humana solo porque lo referimos a un sentido trascendente, o si en sí mismo es distinto de un mero suceso de la naturaleza. Caso de aceptar la segunda postura esto nos conduciría, frente al neokantismo, a un radical cambio de perspectiva, representada, en gran parte, por Welzel quien afirmará: "Los conceptos científicos no son transformaciones diferentes de un idéntico material libre de valores, sino reproducciones de trozos parciales de un ser óntico complejo, que lleva en sí inmanentemente las estructuras legales y diferencias de valor y no las recibe prestadas de la ciencia"28. De ello se sigue que el método no determina el objeto de conocimiento, sino que el método debe orientarse, por necesidad esencial, al objeto que hay que investigar.

\footnotetext{
${ }^{25}$ Radbruch, Gustav, Introducción, op. cit., p.84-86

${ }^{26}$ Larenz, Karl, Metodología, op. cit., p. 121.

${ }^{27}$ Kaufmann, Arthur y Hassemer, Winfried, El pensamiento jurídico contemporáneo, trad. Gil Robles y otros, Debate, Madrid, 1992. p 204-208.

${ }^{28}$ Larenz, Karl, Metodología, op. cit., p. 133-134
} 


\section{ISABEL RUIZ-GALLARDóN}

La crítica de Welzel al neokantismo enlaza, en lo fundamental, con la fenomenología de Edmund Husserl y, especialmente, con la ontología de Nicolai Hartmann.

Para el primero, el derecho tiene la estructura temporal de la historicidad, lo cual significa que no solo "surge" y "perece" en el tiempo (histórico), sino que también participa de la corriente de la historia, que puede también cambiar con la situación histórica y con los hombres para los que tiene valide $z^{29}$.

De aquí resulta, para la interpretación jurídica, lo siguiente: la norma jurídica es, en primer lugar, creada en un determinado tiempo histórico desde la perspectiva de un determinado legislador. Esta voluntad (que no son los actos psíquicos del querer) halla en la obra legal su expresión, y debe tenerse en cuenta en la interpretación de la norma; pero la voluntad del legislador no tiene la última palabra en la interpretación de una ley. De lo que se trata es de interpretar lo que esa norma significa para los hombres que hoy viven bajo ese orden jurídico.

El movimiento fenomenológico realizó importantes aportaciones; en primer lugar, condujo a la idea de que el concepto positivista de ciencia no es suficiente para las ciencias históricas y las del espíritu. La razón de ello (todavía oculta al neokantismo) es que también el concepto positivista de realidad es demasiado estrecho. El idealismo objetivo y la teoría fenomenológica del derecho, a pesar de la diferencia de sus posiciones iniciales, coinciden en que las posiciones del espíritu - entre ellas un orden jurídico vigente - tienen el carácter de lo real. Un derecho positivo existe, si no en el espacio, sí en el tiempo; no es posible, por ello, reducirlo a fenómenos materiales ni físicos, tiene la forma de ser del "valer".

El neokantismo consideraba el modo de realidad de estas formaciones con sentido únicamente como productos de la reflexión científica "ordenadora" y "referida al valor". Sin embargo, se dio cuenta que es inherente al derecho, según su sentido, la pretensión de rectitud en el sentido de "justicia". En otras palabras, que toda norma jurídica y todo instituto jurídico, hacen referencia al mismo tiempo, por su propio sentido, a un sentido total del derecho, a la "idea de derecho".

El neokantismo, sin embargo, sólo comprendió este sentido a priori como un punto de orientación formal. Pero una vez que se tuvo en cuenta la diferencia existente entre las estructuras del ser "natural" y del "espiritual", tuvieron que servirse de nuevos caminos para la formación de los conceptos. A partir de aquí, no parece posible volver a una jurisprudencia formal de conceptos, ni a la jurisprudencia genética de intereses, ni a una ciencia del derecho solo pragmática, ni a una metodología orientada psicológica, sociológica o normológicamente.

\footnotetext{
${ }^{29}$ Ibídem, p. 135-139
} 


\section{LA ACTIVIDAD VALORATIVA DEL JUEZ EN LA JURISPRUDENCIA DE FINALES DEL SIGLO XX}

\subsection{Lo que dice la metodología jurídica sobre la interpretación judicial}

El mayor contacto con el pensamiento jurídico anglosajón y el desarrollo de las tesis neokantianas, fenomenológicas y ontológicas fomentaron, en la época de la postguerra, la renuncia a la lógica de la subsunción y la propensión de la jurisprudencia de los tribunales a la "justicia del caso concreto".

Respecto a los puntos de vista metódicos que han de tenerse en cuenta a la hora de interpretar, no se trata (como en la metodología tradicional) de métodos independientes, ni de reglas rígidas, sino de puntos de vista directivos, de ayudas de orientación, que permiten en su aplicación un margen de libre enjuiciamiento, del mismo modo que la mayoría de las normas jurídicas. Esto no significa, en ningún caso, que el juez pueda utilizar arbitrariamente los puntos de vista metódicos, ni omitir alguno de ellos para llegar al resultado deseado por él.

Muchos de los criterios tradicionales de interpretación (incluyendo los que posibilitan un desarrollo del derecho inmanente a la ley), reciben, en el marco del pensamiento orientado a valores, una nueva perspectiva; de esta manera, mientras que la metodología tradicional ve en la analogía esencialmente un proceso de argumentación lógica, la nueva metodología subraya que en la supuesta similitud se trata de una valoración igual de modo que los casos comparados deben ser iguales en los aspectos que sean decisivos para la valoración del caso ya regulado.

El pensamiento orientado a valores no rechaza la inclusión de la dimensión ética en el hallazgo del derecho. Sostiene que en el caso de un conflicto no soluble entre fidelidad a la ley y justicia del caso, la decisión última la tiene la conciencia del juez, siendo, por ello, de máxima importancia los principios ético-jurídicos en el desarrollo del derecho.

En derecho, igual que en la ética, en última instancia se trata siempre de justificación, de la justificación de su pretensión de validez en conjunto en un determinado orden jurídico y de la resolución particular. ${ }^{30}$

El jurista, con todo, no hace valer inmediatamente los principios éticos últimos que justifican una resolución sino solo cuando no es posible la aplicación del orden jurídico contenido en las leyes y el orden judicial, o cuando es el único modo de evitar una injusticia manifiesta.

Existe, a día de hoy, acuerdo generalizado en que las resoluciones judiciales no estén completamente pre-programadas en las leyes. El juez, no obstante, está vinculado a la ley y al derecho. Esto significa poner en vigor la función de la ley jurídico-constitucionalmente prevista, con los medios de fundamentación y

${ }^{30}$ Larenz Karl, Metodología, op. cit. pp. 141-151. 


\section{ISABEL RUIZ-GALLARDóN}

argumentación jurídicas, al tratar de hallar una resolución justa, y así respetar también la misión y responsabilidad, no sustituibles jurídico-judicialmente, del legislativo.

No podemos perder de vista que la metodología jurídica está condicionada por la Constitución política. En este sentido, Müller distingue la metódica jurídica como el modo efectivamente practicado de trabajo y argumentación de los juristas prácticos, de la metodología de la ciencia del derecho. Müller afirma que "los actos de instancias jurídicas de decisión solo tienen validez legítima si, según las reglas de la metódica, aparecen como reglas de decisión acreditables por normas jurídicas". 31

Por otra parte, frente a la opinión de algunos autores de que los juicios de valor no pueden fundamentarse, Alexy argumenta que se deben hallar reglas según las cuales pueda conducirse un discurso racional sobre la rectitud de los enunciados normativos. El discurso jurídico es un discurso práctico en general, sujeto a más condiciones restrictivas como la vinculación a la ley, la consideración de los precedentes, la inclusión en la dogmática elaborada por la ciencia del derecho y, en el discurso ante el tribunal, las reglas del código procesal. ${ }^{32}$

No se debe, con todo, sobrevalorar la importancia de estas reglas. No son capaces de contestar la pregunta de por qué el jurista se sirve precisamente de estas reglas y formas de interpretación, ni tampoco puede establecer en qué medida intervienen los juicios de valor.

La decisión de a qué valor corresponde la preeminencia en caso de conflicto, no está prefijada. El peso de un valor en el caso particular depende del hecho. Sirven de ayuda en la valoración ciertas reglas de razón. Además importan criterios como la proximidad del valor al hecho, la mayor o menor probabilidad de respetar o lesionar un valor y la imperiosidad de la necesidad. Un límite de estas reglas de preferencia resulta de la igualdad.

Westermann subraya que es necesario reducir el interés a las ideas de apetencia que puedan tener los participantes en un litigio cuando pretenden la consecuencia jurídica más favorable para ellos, y delimitar claramente el concepto de interés en este sentido de las "pautas legales de valoración"33.

Las pautas de valoración (por ejemplo protección del tráfico jurídico, apariencia jurídica, garantía de propiedad...) no son tampoco intereses sino, en último término, consecuencias de la idea de justicia sacadas por el legislador. El juez está ligado a los factores de valoración hallados por el legislador. Por ello, la jurisprudencia de los tribunales es aplicación de las valoraciones legales, a diferencia de la valoración independiente.

\footnotetext{
${ }^{31}$ Ibídem, p. 160.

${ }^{32}$ Ibídem, p. 508.

${ }^{33}$ Larenz, Karl, Metodología, op. cit., pp. 141-142.
} 
En la misma línea, Oscar Adolf Germann, reconoce los méritos de la jurisprudencia de intereses y especialmente la necesidad de una interpretación conforme al fin de la ley, pero estos métodos tienen límites. Por ello es más amplio partir de los valores sociales a los que corresponde la ley. A ello responde el método crítico-valorativo. En él no se trata solo de una valoración independiente por parte del juez, sino de la interpretación atendiendo a las valoraciones que sirven de base a la ley y que son inmanentes a ella ${ }^{34}$.

En Coing se halla una fundamentación de la "jurisprudencia de valoración" que ya no parte de la jurisprudencia de intereses ${ }^{35}$. El enlace entre supuesto de hecho y la consecuencia jurídica, tal como se da en una regla jurídica completa, se basa en una valoración. Es, por tanto, un juicio de valor realizado por el legislador y por el juez y puede estar determinado por puros intereses del que decide, por consideraciones de oportunidad o de justicia.

La aplicación del derecho no es simplemente un proceso de subsunción sino un proceso de actuación de la voluntad dirigida a fines, en el cual juegan el papel decisivo las valoraciones extraídas de la ley, ya sean de índole moral o pragmática. Por ello Coing ve la misión de la jurisprudencia en "elaborar el contenido racional de los valores que sirven de base a la ley, porque sólo así el juez estará en situación de controlarse a sí mismo". Coing, apoyado en Germann, califica este proceder de método crítico-valorativo.

El orden de valores positivizado al que debe orientarse todo jurista llamado a hacer una valoración, se encuentra fijado en todos los órdenes jurídicos civilizados, en la parte de derechos fundamentales, fijados por las respectivas constituciones. Es aquí donde se encuentran valores como la dignidad humana, y principios elevados a rango constitucional, como el principio de igualdad con sus diferentes especializaciones o el principio de libre desarrollo de la personalidad. Todos los preceptos jurídicos deberán interpretarse según el espíritu de este orden de valores.

Surge, sin embargo, la pregunta de si este orden de valores es también un orden jerárquico de valores evidente. Zippelius se plantea así la cuestión: las decisiones valorativas, ¿conducen necesariamente a un subjetivismo o existen valores objetivos y un orden objetivo de valores, que son parte de un mundo espiritual que nos es común? y ¿de qué modo y hasta qué punto podemos conocer un tal orden de valores? Zippelius ve la pauta para las decisiones valorativas en la moral jurídica dominante ${ }^{36}$. Las concepciones ético-jurídicas, encontrarían en el derecho su expresión más importante, especialmente en los derechos fundamentales.

\footnotetext{
${ }^{34}$ Ibídem, p. 143.

${ }^{35}$ Coing. Helmut, Fundamentos de Filosofía del Derecho, trad. J. M. Mauri, Ariel, Barcelona, 1961, p. 122 .

${ }^{36}$ Larenz, Karl, Metodología op. cit. pp. 144-145.
} 


\section{ISABEL RUIZ-GALLARDóN}

Además, las concepciones valorativas dominantes podrían hallar expresión en las costumbres del lugar y en ciertas instituciones de la vida social, como por ejemplo la forma tradicional de matrimonio. Sin embargo, una costumbre tradicional no podría ser ya como tal una pauta para una decisión jurídica valorativa, sino solo cuando es expresión de las concepciones valorativas dominantes, y precisamente porque lo es ${ }^{37}$.

Zippelius halla un nuevo indicio de la moral jurídica dominante en los principios jurídicos elaborados por la jurisprudencia de los tribunales; pero estos indicios dejan sin resolver muchas dudas. Constantemente se encuentran conflictos de valor no resueltos; además, la moral jurídica dominante es variable. Finalmente, en ocasiones queda un ámbito en que la decisión no encuentra pauta segura ni inmediata en el derecho escrito, ni en las concepciones ético-jurídicas vigentes. En tal caso, el juez solo podría resolver según su idea final de justicia y, en último caso, según consideraciones de oportunidad ${ }^{38}$.

Para Esser una nueva idea jurídica halla acceso al derecho vigente de la siguiente manera: "Una problemática real y objetiva obliga al desarrollo de una determinada solución, que primeramente tiene lugar todavía casuísticamente, sin búsqueda ni de pruebas de los principios; luego se apoya pragmáticamente en este o aquel oportuno pasaje textual, respecto al cual se concede - cuando las contradicciones del sistema no pueden ocultarse por más tiempo - que tal pasaje solo se utiliza para apuntalar sistemáticamente un principio jurídico que lo trasciende”39. Esser se enfrenta con la cuestión de cómo se forman tales principios jurídicos y cómo consiguen reconocimiento. Descarta que se deriven inductivamente de la ley, ni tampoco que se deriven deductivamente de un sistema de derecho natural o de un orden jerárquico estable de valores. En ocasiones hace referencia a la naturaleza de la cosa o a una determinada institución, así como a las esferas prepositivas de principios ético-jurídicos y de la convicción general. Los principios, afirma, se forman primero inconscientemente hasta que encuentran una formulación convincente distinta de la mera interpretación de lo positivamente ya existente. La sentencia judicial, en una práctica constante, se convierte entonces en transformadora de los principios prepositivos en normas jurídicas positivas e instituciones ${ }^{40}$.

Queda abierta la pregunta acerca de las conexiones internas de los principios y acerca de su contenido. Los principios jurídicos, tal y como los entiende Esser, ni son proposiciones jurídicas (normas), ni son proposiciones en el sentido de

${ }^{37}$ Zippelius, Reinhold, Teoría general del Estado. Ciencia de la política. ed. electrónica del Instituto de Investigaciones jurídicas de la UNAM, México, 1985 pp. 47-52.

${ }^{38}$ Zippelius, Reinhold, op. cit. p.196.

${ }^{39}$ Larenz, Karl, Metodología, op. cit. pp. 149-150.

${ }^{40}$ Larenz, Karl, Metodología, op. cit. pp. 151. 
la lógica (proposiciones axiomáticas, de las que pudieran derivarse por medio de conclusiones racionales, proposiciones concretas de deber ser). El principio jurídico, se descubre originariamente en el caso concreto. Después es una fórmula para una serie de puntos de vista típicamente pertinentes. Esto significa que, en casos atípicos o cuando hay un cambio en las pautas de valoración de un principio, la solución puede ser precisamente la contraria. Incluso una vez descubierto el principio, su posterior desarrollo en la jurisprudencia es un proceso de continua configuración ${ }^{41}$.

La interpretación y el desarrollo del derecho no son pensables sin un modelo, sin una idea de los principios que integran lo dispar de un sistema. Además, el contenido normativo de la norma, afirma Esser, es determinado siempre por los principios de todo orden fijo y de la creación del derecho. Y es que, ciertamente, un principio se positiviza por la jurisprudencia de los tribunales, siempre que esto no haya sucedido ya por obra de la ley. Los principios tienen ya, entiende Esser, en cuanto prepositivos, un contenido inteligible y enunciable, es decir: que no sólo son formados y llenados de contenido por la jurisprudencia de los tribunales, sino que así mismo indican primero a esta dirección.

Es importante la distinción que hace Esser entre normas y principios, así como la idea de que la mayoría de los principios no son derivados deductivamente de postulados más generales, sino conocidos en el caso, más exactamente: partiendo del examen de la problemática específica de grupos de casos; por tanto, en cierto modo, descubiertos, es decir, hechos conscientes e incluidos en el proceso de desarrollo del derecho.

Al lado de los principios (o ideas directivas) Esser admite otra clase de bases extralegales de valoración: los standars, los modelos o las ideas de valor (por ejemplo: la seguridad en el tráfico). A ellas hacen referencia las mismas leyes, como cláusulas generales. La norma, dirá Esser, no es hallada interpretativamente, en estos casos, partiendo del principio, sino que es creada mediante síntesis judicial; solo la casuística nos comunica lo que es derecho. A pesar de lo anterior, el juez, cuando la ley no le ofrece o puede ofrecer ninguna indicación, no debe conformarse solo con su sentimiento jurídico, o sus valoraciones subjetivas. Existen máximas de decisión y principios de valoración objetivables y comprobables al enjuiciar un caso concreto. Estas bases extralegales de la creación judicial del derecho que expone Esser, estarían, en primer lugar, en las valoraciones expresas del autor de la constitución; luego, en los llamados por Esser standards - el consenso de los pensadores jurídicos de su tiempo - y después, en los principios configurados de equidad judicial. Finalmente, en la naturaleza de la cosa y en las estructuras lógico-objetivas del derecho así como en la doctrina acreditada y en los usos judiciales reconocidos.

\footnotetext{
${ }^{41}$ Larenz, Karl, Metodología, op. cit. p. 432.
} 


\section{ISABEL RUIZ-GALLARDóN}

Arthur Kaufmann ve precisamente en la "naturaleza de la cosa" el concepto clave para la comprensión del proceso de creación del derecho, tanto en el plano de la legislación, como en el de las resoluciones judiciales ${ }^{42}$. Este proceso consiste, precisamente, en poner en concordancia recíproca "deber ser" y "ser". La naturaleza de la cosa es el topos en el que ser y deber ser se encuentran, el punto metódico de unión entre realidad y valor. El pensamiento a partir de la naturaleza de la cosa es pensamiento tipológico. La teoría del derecho y de la creación del derecho de Kaufmann, se fundan en una ontología universal en la que lo susceptible de valor y lo real son pensados, desde un principio, unidos entre sí.

\subsection{Hacia una jurisprudencia de valoración del caso}

Una de las preguntas claves que los juristas se han hecho en los últimos años se refiere a la existencia o no de métodos racionales para crear derecho (independientemente de la ley) de los que el juez se sirve, quizá inconscientemente, siendo luego tarea de la metodología jurídica el hacerlos conscientes. Dos de estos métodos son, por un lado, el modo de pensar tópico, expuesto modernamente por Theodor Viehweg, y, por otro lado, las llamadas "consideraciones jurídico-racionales" de Kriele ${ }^{43}$.

Según Viehweg, en la jurisprudencia no se trata de la realización de principios jurídicos generales que han hallado expresión en las leyes y que han de ser aclarados en su sentido "racional" por medio de la interpretación y ulteriormente desarrollados, sino solo de la resolución justa, siempre adecuada a la cosa, del caso particular. La jurisprudencia - tal es la síntesis fundamental de Viehweg - solo puede satisfacer su peculiar propósito: determinar qué es lo justo aquí y ahora en cada caso; se procede no "deductivo-sistemáticamente" sino "tópicamente".

Viehweg define la tópica (siguiendo a Aristóteles, los retóricos y en especial a Cicerón) como "un procedimiento especial de discusión de problemas", que se caracteriza por el empleo de ciertos puntos de vista, planteamientos y argumentos generales, aceptados como estables: justamente los topoi. Los topoi son puntos de vista polifacéticos, aceptables en todas partes, que se usan en pro y en contra de lo que se opina y puede conducir a lo verdadero. Se emplean para poner en marcha la discusión de un problema y, en cierto modo, abordarlo desde aspectos diferentes, como también para descubrir la conexión comprensiva ya dada, en la que está situado el problema. Pero mientras el pensamiento sistemático deductivo intenta aprehender esta conexión comprensiva como un sistema global, lógico, el pensamiento tópico se centra sólo en el problema mismo. Este pensamiento no conduce a un sistema global sino a una pluralidad de sistemas, sin demostrar su compatibilidad desde un sistema global.

\footnotetext{
${ }^{42}$ Kaufmann, Arthur, -Hassemer, Winfried, op. cit. pp. 206-207.

${ }^{43}$ Larenz, Karl, op. cit., pp. 151-160.
} 
En concreto, Viehweg distingue dos grados de tópica. Con el primero se captan sólo, intencionadamente, puntos de vista positivos o causales que se convierten en un problema. Así se procede casi siempre en la vida diaria. En el segundo grado se buscan puntos de vista y se reúnen en los llamados "catálogos de tópicos" que parecen ajustados a problemas determinados; su función esencial es la de servir a la discusión del problema. Los topoi jurídicos son, según estos "catálogos", argumentos a los que se recurre para la solución de problemas jurídicos y que pueden contar al respecto con la aceptación general.

No es posible indicar con exactitud qué entiende Viehweg propiamente por topoi jurídicos. Aparentemente, considera un topoi toda idea o punto de vista que pueda desempeñar en absoluto un papel, el que sea, en las discusiones jurídicas. Pero quizás Viehweg pasa por alto que el jurista, excluidos los casos límite en que es remitido a su propia valoración, toma el camino del derecho positivo para conseguir resoluciones justas. El derecho positivo adopta aquí la función de una mediación - entre las principales exigencias inmediatamente evidentes de la justicia y la regulación de sectores de vida particulares o situaciones de conflicto - y hace vinculantes determinadas pre-resoluciones. Así el juez, salvo en casos límite, no tiene que realizar inmediatamente la justicia, sino que tiene que encontrar una resolución que, en primer lugar, esté de acuerdo con las reglas del derecho positivo y con los principios de valoración a ellas subyacentes, así como con las pautas reconocidas por el derecho positivo y con las concretizaciones de estas pautas ya contenidas en sentencias judiciales comparables.

Ante el peligro de ver hecha añicos toda la construcción sistemática del orden jurídico, hay que insistir en que una ciencia del derecho que quiere hacer visibles las conexiones de sentido, las peculiaridades estructurales, la contextura espiritual del orden jurídico, tiene que proceder sistemáticamente. Esto no quiere decir que esta ciencia del derecho halla derivado lógica y separadamente las reglas jurídicas o los conceptos jurídicos. Y es que el "pensamiento sistemático” y el "pensamiento problemático" no deben excluirse ${ }^{44}$.

En línea con lo anterior, Martin Kriele llama método de argumentación jurídico-racional a aquel que, en su opinión, permite fundamentar de otro modo las decisiones jurídicas cuando éstas no pueden obtenerse solo de la ley o de los precedentes. La expresión "derecho racional" no la entiende en el sentido de un sistema jurídico-natural o jurídico-racional de normas jurídicas o principios, intemporalmente válidos, pues eso significa salirse de la discusión histórica. Más bien, opina Kriele que todas las decisiones jurídicas, tanto las del legislador como las del juez, precisan justificación (interna) mediante fundamentos racionales ${ }^{45}$.

${ }^{44}$ Viehweg, Theodor, Tópica y jurisprudencia, trad. Luis Díez Picazo, ed. Taurus, 1986, pp. 146-151.

${ }^{45}$ Kriele, Martin, Introducción a la teoría del Estado, trad. Eugenio Bulygin, ed. Depalma, Buenos Aires, 1980, p. 147. 


\section{ISABEL RUIZ-GALLARDóN}

Respecto a las consideraciones jurídico-racionales, Kriele observa que, en primer lugar, hay que tener en cuenta que la estructura de la argumentación jurídico-racional se identifica con la argumentación jurídico-política. Esta consiste a su vez, en una "discusión del pro y el contra" preguntándose al respecto acerca de las consecuencias de las normas propuestas y por su relevancia. La solución del problema solo puede ser recta si soluciona rectamente los problemas concretos, es decir, de un modo justificado. Para ello son siempre imprescindibles consideraciones jurídico-racionales. Estas consistirán en la predicción de las consecuencias esperables que habría de tener la realización de una propuesta normativa, así como en la discusión acerca de la rectitud de la predicción y acerca de la relevancia de los intereses en cuestión. Parece, entonces, que las consideraciones jurídico-racionales son una auténtica valoración de intereses (efectuándose caso por caso, en el sentido de la tópica) ${ }^{46}$. No siempre, sin embargo, está claro qué interés es el más fundamental en cada caso. En realidad, no siempre consigue Kriele evitar con sus tesis el subjetivismo judicial.

\section{ALGUNAS CONCLUSIONES SOBRE LA LABOR DEL JUEZ}

La jurisprudencia de valoración no ha tenido la última palabra en el ámbito de la aplicación judicial del Derecho. Estoy de acuerdo con la advertencia de Friedrich Müller ${ }^{47}$ de que la propuesta tópica de preguntar más allá de la norma y luego pasar por encima de ella, al no parecer ofrecer ninguna otra propuesta para una solución del problema plena de sentido, no es aplicable en este punto al derecho constitucional a causa de la peculiaridad de la constitución como regulación fundamental. Considero también un peligro para la seguridad jurídica algunos intentos actuales de confiar la normativa de la constitución a una dinámica de fluyente historicidad que los jueces deben valorar a la hora de aplicar las normas.

Qué duda cabe de que la jurisprudencia de valoración resulta inmensamente atractiva de cara a la consecución de una justicia más humana, adaptada a las circunstancias del caso concreto. Su implantación, no obstante, exigiría asegurar un alto grado de formación y de honradez de los jueces, algo que no puede dejarse en manos de una esperanza incierta.

Coincido con Ernst Forsthoff y con Carl Schmitt ${ }^{48}$ en que aceptar sin más los presupuestos de la jurisprudencia de valoración provoca la inseguridad de la constitución y, con ello, de las bases de la comunidad política. Corremos el riesgo de diluir el edificio constitucional en mera casuística. Precisamente, la cuestión de

\footnotetext{
${ }^{46}$ Larenz, Karl, Metodología, op. cit. pp.157-160.

${ }^{47}$ Müller Friedrich, Métodos de trabajo del derecho constitucional, ed. Marcial Pons, Madrid, 2006, p.68.

${ }^{48}$ Sosa Wagner, Francisco, Carl Schmitt y Ernst Forsthoff coincidencias y confidencias, Marcial Pons, Madrid, 2008, pp. 37-68.
} 
una posible tiranía de los valores es el objeto de estudio de un próximo artículo, del cual este sienta las bases.

Sin embargo, esto no debe llevarse a extremo pues, la idea de que la aplicación de la ley no se agota en la subsunción sino que exige valoraciones por parte de quien la aplica, y la necesidad de obtener de la constitución las pautas de valoración, hacen imprescindibles la aplicación de métodos "científico-espirituales".

La experiencia atestigua que es imposible crear un código que disponga de una respuesta para todas las cuestiones que surjan, que las leyes no solo tienen lagunas inevitablemente, sino también que sólo puede constatarse donde arraigan en virtud de múltiples consideraciones y mediante juicios muy diversos, entre los que también se encuentran los juicios de valor. La idea hermenéutica fundamental afirma que comprender textos, es decir, el contenido espiritual en ellos expresados, su sentido, es un proceso en el que el sujeto que comprende no se comporta solo receptivamente, sino que también se comporta casi siempre espontáneamente, cuyo resultado trasciende por ello lo que desde un principio estaba decidido en el texto de un modo evidente. Por ello, la aplicación de la ley solo es posible en un proceso continuado de concretización.

Podemos concluir que, al igual que en la doctrina moderna ya no se discute la individualización de las penas y medidas de defensa social en el ámbito penal, del mismo modo, las tendencias actuales cada vez insisten más en la necesaria individualización de las normas también en el ámbito del derecho privado. Este ensanchamiento de la labor creadora e interpretativa de los jueces no es incompatible con los principios de primacía de la ley y de sujeción del juez a ella. Supone, más bien, una superación del conceptualismo jurídico, sustituyéndolo por métodos más flexibles, y una ampliación de la función interpretativa del juzgador. Como señala Legaz y Lacambra, "el juez, que no crea normas jurídicas de carácter general ni puede hacerlo en tanto que actúa como juez, es, sin embargo, auténtico creador de Derecho, un colaborador más - como el legislador y el administrador - en el proceso dinámico de creación del orden jurídico" 49 . En definitiva: las leyes contienen disposiciones generales y no deben entrar en la casuística y el reglamentarismo; son los jueces quienes, como aplicadores del derecho, deben adaptar esas normas a los casos concretos, insistiendo, en todo momento, en que las leyes no pueden dejar de aplicarse en beneficio de una valoración del juez.

\section{BIBLIOGRAFÍA}

CASTÁN TOBEÑAS, J., La formulación judicial del Derecho: jurisprudencia y arbitrio de equidad, 2ª ed. revisada y aumentada, Reus, Madrid, 1954.

${ }^{49}$ Legaz y Lacambra, Luis, Filosofía del Derecho, op. cit., p.423. 
COING. H., Fundamentos de Filosofía del Derecho, trad. J. M. Mauri, Ariel, Barcelona, 1961.

HEGEL, G. W., Lecciones sobre la Filosofía del a Historia Universal, prólogo de Ortega y Gasset, José, trad. Gaos, José, 5ª reimpr., Alianza, Madrid, 1994.

KAUFMANN, A. y HASSEMER, W., El pensamiento jurídico contemporáneo, trad. Gil Robles y otros, Debate, Madrid, 1992.

KELSEN, H., Teoría Pura del Derecho, Porrúa, 9ªed, México, 1997.

KRIELE, M., Introducción a la teoría del Estado, trad. Eugenio Bulygin, Depalma, Buenos Aires, 1980.

LARENZ, K., La Filosofía Contemporánea del Derecho y del Estado, Revista de Derecho Privado, trad. E. Galán Gutiérrez y A. Truyol y Serra. Prólogo Luis Legaz y Lacambra, Madrid, 1942.

LARENZ, K., Metodología de la Ciencia del Derecho, Ariel, Barcelona, 1994.

LAREN,. K., Derecho Justo. Fundamentos de ética jurídica, trad. Luis Díez Picazo, Cívitas, Madrid, 1993.

LEGAZ Y LACAMBRA, L., Filosofía del Derecho, $5^{\text {a }}$ ed. revisada y aumentada, Bosch, Barcelona, 1979.

MÜlLER, F., Métodos de trabajo del derecho constitucional, Marcial Pons, Madrid, 2006.

RADBRUCH, G., Filosofía del Derecho, Revista de Derecho Privado, $4^{\mathrm{a}}$ ed., Madrid, 1959.

RADBRUCH, G., Introducción a la Filosofía del Derecho trad. W. Roces, FCE, $5^{\text {a }}$ reimpr., México, 1993.

RUIZ-GALLARDÓN, I., Una aproximación a la equidad desde la teoría y la dogmática jurídicas, servicio de publicaciones de la Universidad Complutense de Madrid, Madrid, 2002.

SPOTA, A. G., Tratado de Derecho Civil, Tomo I, parte general, vol. 1, Depalma, Buenos Aires, 1947.

SOSA WAGNER, F., Carl Schmitt y Ernst Forsthoff coincidencias y confidencias, Marcial Pons, Madrid, 2008.

STAMMLER, R., Tratado de Filosofía del Derecho, Reus, Madrid, 2008.

STENBERG, T., Introducción a la Ciencia del Derecho, Labor, Barcelona, 1930 (hay una $2^{\mathrm{a}}$ ed.: 1940; traducción de Rovira).

VIEHWEG, T., Tópica y jurisprudencia, trad. Luis Díez Picazo, Taurus, 1986.

ZIPPELIUS, R., Teoría general del Estado. Ciencia de la política, edición electrónica del Instituto de Investigaciones jurídicas de la UNAM, México, 1985. 